\title{
Reductie wachttijd voor aanvang van de klinische fase en strategisch studeergedrag
}

\author{
N. Leffers, B.T. Onnes, J. Cohen-Schotanus, J.R. Huizenga
}

\section{Samenvatting}

Inleiding: Bij de Faculteit der Medische Wetenschappen in Groningen bestaat sinds de invoering van de nieuwe klinische fase in 1999 geen wachttijd meer voor de co-assistentschappen. Een aantal studenten lijkt te reageren met strategisch studiegedrag, zodat het begin van de klinische fase uitgesteld kan worden. Het doel van dit onderzoek is in kaart te brengen hoeveel studenten strategisch studiegedrag vertonen, welke redenen studenten hiervoor aanvoeren en wat de gevolgen kunnen zijn voor het dreigend tekort aan artsen en specialisten.

Methode: Een vragenlijst werd voorgelegd aan alle eerste- tot en met vierdejaars studenten. Voor statistische analyse werd gebruik gemaakt van frequentieanalyses en de $\chi^{2}$-toets.

Resultaten: De helft van de studenten is van plan langer dan 6.5 jaar over de studie te doen. De belangrijkste redenen hiervoor zijn bezigheden naast de studie en de wens naar het buitenland te gaan. In de loop van de studie neemt het aantal studenten toe (van $11 \%$ in jaar 1 tot $33 \%$ in jaar 4) dat van plan is bewuste studievertraging op te lopen. Als belangrijkste redenen voor vertraging werden aangegeven de angst een deel van hun sociaal leven te verliezen en het gevoel aan vrijheid in te boeten.

Discussie en conclusie: Veel studenten geven aan de basisopleiding niet binnen 6.5 jaar te willen afronden, hetgeen gevolgen kan hebben voor een vervolgopleiding. (Leffers $N$, Onnes BT, Cohen-Schotanus J, Huizenga JR. Reductie wachttijd voor aanvang van de klinische fase en strategisch studeergedrag. Tijdschrift voor Medisch Onderwijs 2004;23(2):100-105.)

\section{Inleiding}

Bij de Faculteit der Medische Wetenschappen (FMW) in Groningen bestaat sinds 1999 geen wachttijd voor de klinische fase (de co-assistentschappen). Voorheen werd de wachttijd vaak gebruikt voor een (geplande) studiepauze, die zowel in binnenals buitenland kon worden ingevuld. Sedert het vervallen van de wachttijden zijn dergelijke studiepauzes formeel gezien niet meer mogelijk en zouden de studenten sneller moeten afstuderen.

In de huidige klinische fase kunnen studenten van de FMW drie keer per jaar met de co-assistentschappen beginnen (in januari, mei en september). Studenten die tijdens het tweede of derde instroommoment met de co-assistentschappen starten, doen in principe eerst een wetenschappe- lijke stage of volgen keuzeonderwijs (keuzecursussen). Per loting worden de studenten verdeeld over acht ziekenhuizen en in principe voor twee jaar ingedeeld. ${ }^{1} \mathrm{Per}$ instroommoment beginnen 90 studenten tegelijk met de klinische fase, zodat coassistentplaatsen niet verloren gaan en er niet opnieuw wachttijden ontstaan.

De verdeling van een jaarcohort (circa 300 studenten) over de instroommomenten is vaak een moeizame aangelegenheid, aangezien de plannen van studenten en faculteit niet altijd met elkaar overeenkomen. Er bestaat dan ook een spanningsveld tussen individuele vrijheid en facultaire indelingsregels. Het resultaat is dat er studenten zijn die gedwongen worden sneller met de klinische fase te beginnen dan zij zelf willen, tenzij duide- 
lijke individuele afspraken gemaakt zijn. Een aantal studenten reageert hierop met strategisch studiegedrag. ${ }^{2-3}$ Door bijvoorbeeld in het derde jaar te zakken voor een trimester wordt indeling voor de klinische fase voorkomen en wordt het startmoment van het co-assistentschap uitgesteld.

Wij vroegen ons af hoe studenten tegen hun opleidingstraject aankijken en wat de rol hierin is van het afschaffen van de wachttijd. Hiertoe zijn de volgende onderzoeksvragen geformuleerd:

- Is de aanvangsleeftijd van studenten veranderd sinds de nieuwe toelatingsprocedure?

- Hoe lang zijn studenten van plan over hun basisopleiding te doen?

- Hoe kijken ze tegen de facultaire indeling van de klinische fase aan?

- Welke redenen spelen een rol bij bewuste studievertraging?

- In hoeverre speelt de leeftijd bij aanvang van de studie een rol?

- Gaan studenten in de loop der jaren anders tegen hun opleidingstraject aankijken?

\section{Methode}

Er werd een vragenlijst ontwikkeld. De vragenlijst werd samengesteld op basis van mogelijke redenen voor strategisch zakken, zoals is aangegeven door enkele tweede- en derdejaars studenten tijdens spreekuren van de studieadviseurs. De conceptvragen zijn vervolgens voorgelegd aan 6 studenten en op basis van hun reactie is een definitieve vragenlijst samengesteld. Deze lijst is in juni 2002 voorgelegd aan alle eerste- tot en met vierdejaars studenten. Voor de statistische analyse is gebruik gemaakt van frequentieanalyses. Verschillen tussen groepen zijn op significantie getoetst met behulp van de $\chi^{2}$ toets.

\section{Resultaten}

In juni 2002 is de vragenlijst voorgelegd aan 953 studenten. Uit jaar 1 vulden 241 studenten $(84 \%)$ de vragenlijst in. In jaar 2 waren dit 191 studenten (77\%). De respons in jaar 3 en 4 bedroeg $88 \%(n=193)$ en $72 \%(n=144)$. De totale respons bedroeg $81 \%$. De algemene kenmerken van de studenten staan beschreven in tabel 1 .

\section{Vernieuwde toelatingsprocedure}

Bij aanvang van de studie geneeskunde was in elk studiejaar de meerderheid van de studenten 20 jaar of jonger en werd de helft van de studenten direct na de middelbare school ingeloot (zie tabel 1). Studenten uit de verschillende studiejaren verschillen niet significant in leeftijd bij aanvang van de studie $(\mathrm{p}=0.428)$. Tussen de gestarte jaarklassen is geen verschil in het aantal jaren tussen afronding van de middelbare school en aanvang van de studie geneeskunde $(\mathrm{p}=0.170)$.

\section{Geplande studieduur en studievertraging}

Van alle studenten is $53 \%$ van plan om binnen 6,5 jaar af te studeren en 35\% binnen 7 jaar. Echter, 10\% wil langer dan 7 jaar over de studie doen. De verschillen in geplande studieduur tussen de verschillende jaren zijn niet significant.

Van de studenten die bij aanvang 20 jaar of jonger waren, is $50 \%$ van plan om binnen 6,5 jaar af te studeren. Van de bij aanvang 21 - en 22 -jarigen is dit $67 \%$ en van de studenten die bij aanvang van de studie 23 jaar of ouder waren is $74 \%$ van plan om binnen 6,5 jaar af te studeren. Het verschil tussen studenten van 20 jaar of jonger en de bij aanvang oudere studenten in geplande studieduur is significant $(\mathrm{p}=0.004)$.

In het eerste jaar is $11 \%$ van de studenten van plan om studievertraging op te lopen. Dit percentage stijgt tot 33\% in jaar 4. Het verschil tussen jaar 1 en jaar 2, 3 en 4 in geplande studievertraging is signifi- 
Tabel 1. Algemene kenmerken van studenten per jaar en in het totaal, $\mathrm{N}(\%)$.

\begin{tabular}{|c|c|c|c|c|c|}
\hline Kenmerken studenten & jaar 1 & jaar 2 & jaar 3 & jaar 4 & Totaal \\
\hline \multicolumn{6}{|l|}{ Geslacht } \\
\hline Vrouw & $170(71)$ & $129(68)$ & $137(71)$ & $93(65)$ & $529(69)$ \\
\hline Man & $71(29)$ & $62(32)$ & $56(29)$ & $51(35)$ & $240(31)$ \\
\hline \multicolumn{6}{|c|}{ Leeftijd bij aanvang studie } \\
\hline $17 / 18$ & $121(50)$ & $80(42)$ & $83(43)$ & $58(40)$ & $342(44)$ \\
\hline $19 / 20$ & $87(36)$ & $78(41)$ & $79(41)$ & $57(40)$ & $301(39)$ \\
\hline $21 / 22$ & $25(10)$ & $27(14)$ & $22(11)$ & $17(12)$ & $91(12)$ \\
\hline $23+$ & $7(3)$ & $6(3)$ & $8(4)$ & $10(7)$ & $31(4)$ \\
\hline$?$ & $1(0)$ & $0(0)$ & $1(1)$ & $2(1)$ & $4(0)$ \\
\hline \multicolumn{6}{|c|}{$\begin{array}{l}\text { Aantal jaren tussen afronding middelbare school } \\
\text { en start studie }\end{array}$} \\
\hline Direct & $129(54)$ & $95(50)$ & $98(51)$ & $65(45)$ & $387(50)$ \\
\hline 1 jaar & $63(26)$ & $46(24)$ & $42(22)$ & $44(31)$ & $195(25)$ \\
\hline 2 jaar & $31(13)$ & $25(13)$ & $34(18)$ & $16(11)$ & $125(14)$ \\
\hline $3+$ & $16(7)$ & $22(12)$ & $19(10)$ & $19(13)$ & $76(10)$ \\
\hline$?$ & $2(1)$ & $3(2)$ & $0(0)$ & $0(0)$ & $5(0)$ \\
\hline \multicolumn{6}{|c|}{ Studievertraging op dit moment } \\
\hline Geen & $216(90)$ & $137(72)$ & $118(61)$ & $68(47)$ & $539(70)$ \\
\hline 1 of 2 trimesters & $19(8)$ & $30(16)$ & $54(28)$ & $54(38)$ & $157(20)$ \\
\hline 3 of 4 trimesters & $4(2)$ & $18(9)$ & $10(5)$ & $18(13)$ & $50(7)$ \\
\hline 5 trimesters of meer & $1(0)$ & $6(3)$ & $11(6)$ & $4(3)$ & $22(3)$ \\
\hline \multicolumn{6}{|l|}{ Geplande studieduur } \\
\hline 6,5 jaar & $133(55)$ & $87(46)$ & $102(53)$ & $87(60)$ & $409(53)$ \\
\hline 6,7-7 jaar & $92(38)$ & $77(40)$ & $58(30)$ & $41(28)$ & $268(35)$ \\
\hline 7-8 jaar & $10(4)$ & $19(10)$ & $22(11)$ & $11(8)$ & $62(8)$ \\
\hline 8 jaar of langer & $3(1)$ & $4(2)$ & $6(3)$ & $4(3)$ & $17(2)$ \\
\hline$?$ & $3(1)$ & $4(2)$ & $5(3)$ & $1(1)$ & $13(1)$ \\
\hline
\end{tabular}

$?=$ blanco of niet van toepassing.

cant $(\mathrm{p}<0.001)$. Mannelijke studenten zijn vaker dan vrouwelijke studenten van plan om studievertraging op te lopen met als doel de klinische fase uit te stellen $(\mathrm{p}=0.005)$.

Studenten die bij aanvang van de studie 20 jaar of jonger waren, geven in $26 \%$ aan bewust te willen vertragen om het startmoment van de klinische fase uit te stellen. Dit in tegenstelling tot de bij aanvang 21 jaar en oudere studenten $(9 \%, \mathrm{p}<0.001)$.

Studenten die direct na de middelbare school met de studie geneeskunde beginnen, vertragen significant vaker $(p=0.001)$ dan studenten die na hun middelbare school één of meerdere jaren iets anders hebben gedaan. Tussen studenten die één of meerdere jaren iets anders doen, bestaat geen verschil in geplande studievertraging met tot doel het uitstellen van de klinische fase.

\section{Facultaire indeling}

Een aanzienlijk percentage (29\%) ziet graag een eigen indeling met onbekende wachttijd. Het merendeel van de studenten $(67 \%)$ geeft de voorkeur aan een facultaire indeling zonder wachttijd. Daar- 
Tabel 2. Redenen die studenten aangeven voor het feit dat zij langer dan 6.5 jaar over de studie geneeskunde zullen doen $(n=360)$.

\begin{tabular}{lcc}
\hline Langer dan 6.5 jaar, omdat ... & \% Eens & \% Oneens \\
\hline De studie te zwaar is. Ik heb meer tijd nodig & 29 & 71 \\
Ik tijd besteed aan andere dingen (werk/sport/vereningingsbestuur/ & 73 & 27 \\
andere studie/privé-zaken), waardoor de studie langer duurt & & \\
Ik tijd besteed aan onderzoek (Junior Scientific Masterclass) & 26 & 74 \\
Ik mijn eigen studieperioden indeel & 36 & 64 \\
Ik graag naar het buitenland wil & 75 & 25 \\
Ik mezelf te jong vind om na 6 jaar arts te zijn & 43 & 57 \\
\hline
\end{tabular}

Tabel 3. Vergelijking van de waarschijnlijkheid van redenen tot uitstelgedrag volgens vertragers en niet-vertragers, $N(\%)$.

\begin{tabular}{lccccccc}
\hline Reden uitstelgedrag & \multicolumn{3}{c}{ Vertragers } & \multicolumn{3}{c}{ Niet-vertragers } \\
\cline { 2 - 8 } & Eens & Oneens & $?$ & Eens & Oneens & $?$ \\
\hline Het willen hebben van een vrije periode & $142(85)$ & $20(12)$ & $6(4)$ & $436(80)$ & $89(16)$ & $18(3)$ \\
Angst sociaal leven te verliezen* & $114(68)$ & $11(26)$ & $43(7)$ & $296(55)$ & $226(42)$ & $21(4)$ \\
Gevoel te jong te zijn om arts te worden & $119(71)$ & $41(24)$ & $8(5)$ & $339(62)$ & $180(33)$ & $24(4)$ \\
Gevoel vrijheid te verliezen* & $127(76)$ & $35(21)$ & $6(4)$ & $352(67)$ & $168(31)$ & $23(4)$ \\
Het willen doen van buitenlandse stage & $127(76)$ & $36(21)$ & $5(3)$ & $408(75)$ & $112(21)$ & $23(4)$ \\
$\begin{array}{l}\text { In mijn omgeving zijn er mensen die } \\
\text { strategisch zakken om later met de } \\
\text { co-schappen te kunnen beginnen* }\end{array}$ & $133(79)$ & $25(15)$ & $10(6)$ & $193(36)$ & $223(41)$ & $127(23)$ \\
$\begin{array}{l}\text { Het is mij opgevallen dat studenten het } \\
\text { begin van hun co-schappen uitstellen* }\end{array}$ & $144(86)$ & $17(10)$ & $7(4)$ & $269(50)$ & $171(32)$ & $103(19)$ \\
$\begin{array}{l}\text { Als co-assistenten een vergoeding zouden } \\
\text { krijgen, wil men eerder beginnen met de } \\
\text { co-schappen }\end{array}$ & $101(60)$ & $60(36)$ & $7(4)$ & $342(63)$ & $164(30)$ & 37 & $(7)$ \\
$\begin{array}{l}\text { Als 24-jarige ben je naar mijn mening te jong } \\
\text { om zelfstandig als arts werkzaam te zijn* }\end{array}$ & $88(52)$ & $75(45)$ & $5(3)$ & $190(35)$ & $341(63)$ & $12(2)$ \\
\hline
\end{tabular}

${ }^{*}=$ verschil tussen vertragers en niet-vertragers significant bij $p<0.05 . ?=$ blanco of niet van toepassing.

entegen geldt dat $49 \%$ van de studenten die van plan zijn studievertraging op te lopen om hun klinische fase uit te stellen, de voorkeur geeft een aan een eigen indeling met onbekende wachttijd. De voorkeur voor de mogelijke instroommomen- ten in de klinische fase is evenredig verdeeld over januari $31 \%$, mei 34\% en september 29\%. Globaal 5\% per jaargroep wil of kan pas 12 maanden na afronding van de verplichte onderdelen uit de doctoraal fase instromen in de klinische fase. 


\section{Motivatie voor studievertraging}

De studenten die van plan zijn langer dan 6.5 jaar over hun studie geneeskunde te doen, geven als voornaamste redenen dat ze graag naar het buitenland willen en dat ze tijd willen besteden aan andere zaken, waardoor de studie langer duurt (tabel 2).

Studenten, die van plan zijn te vertragen om de co-assistentschappen uit te stellen, verschillen significant van niet-vertragers op de volgende punten (tabel 3). Zij blijken vaker strategische zakkers in hun omgeving te hebben $(\mathrm{p}<0.001)$. Het valt hen vaker op dat andere studenten het begin van de klinische fase uitstellen $(\mathrm{p}<0.001)$. Tevens geven vertragers vaker aan bang te zijn hun sociaal leven te verliezen en het gevoel te hebben hun vrijheid op te moeten geven $(\mathrm{p}<0.001$, resp. $\mathrm{p}=0.031)$. Opvallend is het feit dat juist niet-vertragers het vaker dan vertragers eens zijn met de stelling dat je als 24-jarige te jong bent om zelfstandig als arts werkzaam te zijn $(\mathrm{p}<0.001)$.

Studenten die 20 jaar of jonger zijn bij aanvang van de studie verschillen van studenten die bij aanvang minstens 21 jaar oud zijn op de volgende punten. Ten eerste geven ze significant vaker aan dat ze zichzelf te jong te vinden om arts te zijn na 6 jaar $(\mathrm{p}<0.001)$. Daarnaast is een aanzienlijk percentage $(37 \%)$ van mening dat je als 24-jarige te jong bent om zelfstandig als arts werkzaam te zijn.

\section{Discussie en conclusie}

Deze studie laat zien dat $45 \%$ van de geneeskunde studenten aan de Faculteit der Medische Wetenschappen te Groningen niet binnen 6,5 jaar denkt af te studeren en dat een groot deel van de studenten hun studie moedwillig verlengt. De voornaamste motivatie hiervoor is de wens tijd te kunnen besteden aan andere zaken en een periode in het buitenland door te brengen. Het aantal studenten dat bewust van plan is studievertraging op te lopen om de klinische fase uit te stellen, neemt gedurende de studie toe met als belangrijkste motivatie de ongerustheid een deel van hun sociaal leven te verliezen en het gevoel te hebben aan vrijheid in te boeten. Er zijn ons geen cijfers bekend van andere faculteiten.

De derdejaars studenten zijn de eerste lichting sinds de verandering van de toelatingsprocedure in 1999, waarbij studenten met een acht of hoger direct worden toegelaten en het aantal keren dat een student mee mag loten beperkt wordt. Op basis van deze nieuwe regels werd verwacht dat de gemiddelde aanvangsleeftijd zou afnemen. Er bestaan tussen de studiejaren echter geen significante verschillen in aanvangsleeftijd noch in het aantal jaren tussen afronding van de middelbare school en aanvang van de studie geneeskunde. De veranderde toelatingsprocedure heeft dus tot op dit moment geen invloed gehad op de aanvangsleeftijd en het aantal jaren tussen afronding van middelbare school en aanvang van de studie geneeskunde.

De in 1999 ingevoerde geautomatiseerde loting voor de co-assistentschappen aan de Rijksuniversiteit Groningen wordt door studenten wisselend ervaren. ${ }^{1}$ Voorkeur voor een eigen indeling met onbekende wachttijd wordt vooral aangegeven door studenten die in de huidige situatie bewust studievertraging oplopen om de aanvang van de klinische fase uit te stellen. Het aantal studenten (ongeveer een vierde) dat om deze reden bewust studievertraging wil oplopen, is aanzienlijk en misschien door onze cijfers onderschat. De enquête is afgenomen in juni en een deel van de derdejaars studenten en vierdejaarsstudenten die misschien reeds uitstelgedrag vertoonden was afwezig. Opvallend is verder dat pas in de loop van 
de studie het besef toeneemt dat men te jong zou zijn om zelfstandig als arts te fungeren.

De resultaten van dit onderzoek zijn relevant voor de discussie rondom het dreigend tekort aan artsen en specialisten in de toekomst. Uit onderzoek is bekend dat het opleiden van artsen zeven jaar langer duurt dan gewenst is. ${ }^{4}$ De medische faculteiten worden door de overheid aangespoord maatregelen te nemen om dit tekort tegen te gaan. Van diverse kanten wordt hieraan gewerkt door bijvoorbeeld de instroomcapaciteit te vergroten en, zoals wij hier bespreken, de wachttijden voor de co-assistentschappen te reduceren. ${ }^{5-6}$ Het verkorten van de basisopleiding kan, zoals wij hier tonen, op weerstand onder de studenten stuiten.

$\mathrm{Om}$ in de toekomst problemen te voorkomen is het belangrijk voorlichting te geven over het opleidingstraject en mogelijkheden tot alternatieve trajecten te ontwikkelen.

\section{Literatuur}

1. Huizenga JR, Bijl GK. Geautomatiseerde loting voor de co-assistentschappen in Groningen. Tijdschrift voor Medisch Onderwijs 2001;20:257-61.
2. Schouwenburg HC. Uitstelgedrag bij studenten [dissertatie]. Rotterdam; 1994.

3. Eerde W van. A meta-analytically derived nomological network of procrastination. Personality and Individual Differences 2003;35:1410-8.

4. Velden LFJ van der, Heiligers PhJM, Hingstman L. Een studie van jaren: vertragingen in de opleiding tot arts. Med Contact 2003;58:694-7.

5. Meyboom-de Jong B, Schmit Jongbloed LJ, Willemsen MC, editors. De arts van straks - een nieuw medisch opleidingscontinuüm. Wijk bij Duurstede: Hentenaar; 2002.

6. Cohen-Schotanus J, Reinders JJ, Agsterribbe J, Meyboom-de Jong B. Tien jaar arts: een longitudinaal onderzoek naar de loopbaan van artsen die hun studie begonnen in Groningen. Ned Tijdschr Geneeskd 2002;146:2474-8.

De auteurs:

Mw. N. Leffers is vijfdejaars geneeskunde student. Mw. B.T. Onnes is vijfdejaars geneeskunde student. Dr. J. Cohen-Schotanus is hoofd van de afdeling Onderwijs en Kwaliteitszorg van het Onderwijsinstituut. Dr. ing. J.R. Huizenga is programmamanager klinische fase en keuzeonderwijs aan het Onderwijsinstituut. Allen zijn verbonden aan de Faculteit der Medische Wetenschappen, Rijksuniversiteit Groningen.

Correspondentieadres:

Dr. ing. J.R. Huizenga, Onderwijsinstituut, Faculteit der Medische Wetenschappen, Antonius Deusinglaan 1, 9713 AV Groningen, tel: 050-3632877, fax: 050-3632596, email: j.r.huizenga@med.rug.nl.

\section{Summary}

Introduction: After the implementation of the new clinical phase in the Faculty of Medical Sciences in Groningen, the Netherlands, there are no longer waiting times before the start of clerkship. A number of students seems to respond to this new situation by using delaying tactics to postpone the start of clinical training. The purpose of this study was to determine how many students do so, why they do so and what consequences this may have in view of the impending shortage of doctors and specialists in the Netherlands.

Methods: In June 2002 a questionnaire was administered to all students in years 1 through 4. For statistical analysis frequency analyses and the $\chi^{2}$ test were used.

Results: Half of the students were planning to take longer than 6.5 years to complete their studies. The main reasons they gave were extracurricular activities and the wish to spend some time abroad. Over the course of the undergraduate curriculum there is an increase in the number of students who are deliberately planning to delay graduation, from $11 \%$ in year 1 to $33 \%$ in year 4 . The main reasons that students give are the fear to lose their social life and the feeling that they are too young to be a doctor.

Conclusion: Many students show reluctance to complete their undergraduate medical training within 6.5 years. This may have consequences for postgraduate training programmes. (Leffers N, Onnes BT, Cohen-Schotanus J, Huizenga JR. The reduction of waiting time before the start of the clinical phase and students' strategies to delay graduation. Dutch Journal of Medical Education 2004;23(2):100-105.) 